\title{
Everolimus in the management of metastatic renal cell carcinoma: an evidence-based review of its place in therapy
}

This article was published in the following Dove Press journal:

Core Evidence

I September 2016

Number of times this article has been viewed

\section{Sebastiano Buti' \\ Alessandro Leonetti ${ }^{1}$ \\ Alice Dallatomasina ${ }^{2}$ \\ Melissa Bersanelli'}

'Medical Oncology Unit, University Hospital of Parma, Parma, ${ }^{2}$ Division of Experimental Oncology, San Raffaele Scientific Institute, Milan, Italy
Correspondence: Sebastiano Buti Medical Oncology Unit, University Hospital of Parma, Via Gramsci I4, 43I00

Parma, Italy

Tel +39 052I 702316

Email sebabuti@libero.it
Introduction: Renal cell carcinoma (RCC) is the most common type of kidney cancer in adults, and its pathogenesis is strictly related to altered cellular response to hypoxia, in which mTOR signaling pathway is implicated. Everolimus, an mTOR serine/threonine kinase inhibitor, represents a therapeutic option for the treatment of advanced RCC.

Aim: The objective of this article is to review the evidence for the treatment of metastatic RCC with everolimus.

Evidence review: Everolimus was approved for second- and third-line therapy in patients with advanced RCC according to the results of a Phase III pivotal trial that demonstrated a benefit in median progression-free survival of $\sim 2$ months compared to placebo after failure of previous lines of therapy, of which at least one was an anti-VEGFR tyrosine kinase inhibitor (TKI). The role of this drug in first-line setting has been investigated in Phase II trials, with no significant clinical benefit, even in combination with bevacizumab. Everolimus activity in non-clear cell RCC is supported by two randomized Phase II trials that confirmed the benefit in second-line setting but not in first line. Recently, two randomized Phase III trials (METEOR and CheckMate 025) demonstrated the inferiority of everolimus in second-line setting compared to the TKI cabozantinib and to the immune checkpoint inhibitor nivolumab, respectively. Moreover, a recent Phase II study demonstrated a significant benefit for the second-line combination treatment with everolimus plus lenvatinib (a novel TKI) in terms of progression-free survival and overall survival compared to the single-agent everolimus. Basing on preclinical data, the main downstream effectors of mTOR cascade, S6RP and its phosphorylated form, could be good predictive biomarkers of response to everolimus. The safety profile of the drug is favorable, with a good cost-effectiveness compared to second-line sorafenib or axitinib, and no significant impact on the quality of life of treated patients has been found.

Conclusion: Everolimus still represents a current standard of treatment for RCC progressive to previous treatment lines with VEGFR-TKI. The evidence about two new molecules, cabozantinib and nivolumab, successfully tested head-to-head with everolimus in recently published Phase III trials, will determine the shift of everolimus to the third-line setting and subsequent lines of treatment.

Keywords: everolimus, afinitor, evidence-based review, renal cell carcinoma, RCC

\section{Core evidence clinical impact summary for everolimus}

Outcome Evidence Implications

measure

Disease-oriented evidence

Clear cell renal Clinical trials cell carcinoma

Everolimus consistently demonstrated efficacy in the treatment of metastatic clear cell renal cell carcinoma after previous VEGFRtyrosine kinase inhibitor failure; therefore, it is a standard of care in second- or third-line therapy. In second-line setting, it might be

(Continued) 


\begin{tabular}{|c|c|c|}
\hline $\begin{array}{l}\text { (Continued) } \\
\text { Outcome } \\
\text { measure }\end{array}$ & Evidence & Implications \\
\hline $\begin{array}{l}\text { Non-clear } \\
\text { cell renal cell } \\
\text { carcinoma }\end{array}$ & Clinical trials & $\begin{array}{l}\text { replaced by two emerging molecules (cabozantinib and } \\
\text { nivolumab). Contrariwise, everolimus employment in first- } \\
\text { line setting alone or in combination with bevacizumab is not } \\
\text { supported by evidence. Combination therapy with lenvatinib } \\
\text { could be a future choice for the treatment of metastatic renal cell } \\
\text { carcinoma after failure of previous tyrosine kinase inhibitor } \\
\text { Everolimus is recommended as second-line treatment in patients } \\
\text { with non-clear cell renal cell carcinoma after sunitinib failure } \\
\text { but not in first-line setting. It seems to have stronger activity on } \\
\text { chromophobe renal cell carcinomas }\end{array}$ \\
\hline $\begin{array}{l}\text { Patient- } \\
\text { oriented } \\
\text { evidence }\end{array}$ & Clinical trials & $\begin{array}{l}\text { Everolimus is well tolerated and has a relatively low rate of } \\
\text { adverse events. Among class-specific adverse events, nonspecific } \\
\text { interstitial pneumonitis is fully reversible in } 54 \% \text { of cases } \\
\text { No significant changes in quality of life and physical functioning } \\
\text { were observed }\end{array}$ \\
\hline $\begin{array}{l}\text { Economic } \\
\text { evidence }\end{array}$ & $\begin{array}{l}\text { Cost- } \\
\text { effectiveness } \\
\text { analyses }\end{array}$ & $\begin{array}{l}\text { Everolimus is more expensive than best supportive care for } \\
\text { treatment of metastatic renal cell carcinoma patients after failure of } \\
\text { previous VEGFR but more cost-effective than sorafenib or axitinib } \\
\text { after prior sunitinib failure }\end{array}$ \\
\hline
\end{tabular}

\section{Introduction}

Renal cell carcinoma ( $\mathrm{RCC}$ ) is the most common type of kidney cancer in adults, and it could occur as a sporadic or hereditary malignancy; clear cell RCC (ccRCC) is the most frequent subtype of sporadic RCC (70\%-85\%), while other variants include papillary RCC (pRCC; 7\%-15\%) and chromophobe RCC (chRCC; 5\%-10\%). ${ }^{1}$

The pathogenesis of ccRCC is mainly related to two molecular events: loss of function of VHL gene and overexpression of the HIF. The protein encoded by VHL gene is appointed to degrade oxygen-regulated subunit of HIF- $1 \alpha$, a protein that dimerizes with constitutively expressed HIF-1 $\beta$ to form a heterodimeric transcriptional factor that regulates cellular response to hypoxia. Once dimerized, HIF induces the transcription of VEGF, PDGF, and TGF- $\beta .^{2}$

The reduced activity of VHL gene results in constitutive expression of HIF-1 $\alpha$ protein, thereby activating the hypoxic response even in the absence of a hypoxic signal, such as neoangiogenesis. ${ }^{3}$ The deregulation of cell homeostasis pathway is critical in ccRCC development. ${ }^{4}$ However, loss of VHL function alone is not sufficient for ccRCC initiation, and a higher number of genetic or epigenetic events are required. ${ }^{5}$

More recently, several studies suggest the implication of mTOR signaling pathway in the growth of RCC..$^{6-9}$

The VHL/HIF and PI3K/AKT/mTOR pathways are involved in a large cross talk, contributing to ccRCC development. As already mentioned, HIF upregulation due to VHL loss of function promotes the expression of a variety of growth factors, including PDGF and VEGF. ${ }^{2}$ The overexpressed growth factors may activate the PI3K/AKT/mTOR pathway through tyrosine kinase receptors, with a subsequent activation of mTOR that promotes HIF expression, ${ }^{10,11}$ therefore triggering a positive feedback loop. ${ }^{12}$ We propose a discussion of this pathway to better understand carcinogenesis, mechanism of action, and therapeutic implications of the targeted drug everolimus.

\section{Mechanism of action $\mathrm{PI}$ KK/AKT/mTOR pathway}

The PI3K/AKT/mTOR is an intracellular signaling pathway involved in various cellular activities resulting in cell proliferation and survival, differentiation, chemotaxis, molecular trafficking, and glucose homeostasis. The implication of this pathway in cancer development and diabetes has been widely investigated. Its deregulation may lead to anchorage-independent growth, increased proliferative potential, increased cell motility, metastasis, and evasion from apoptosis (Figure 1). ${ }^{13}$

$\mathrm{PI} 3 \mathrm{~K}$ is an intracellular transducer enzyme that phosphorylates the membrane PIP2 to generate PIP3. PI3K can be directly activated by $\mathrm{G}$ protein-coupled receptors and tyrosine kinase receptors, ${ }^{14}$ or indirectly through the Ras-ERK pathway. ${ }^{15}$ Downstream, PIP3 regulates the membrane migration and activation of PDK1 that sequentially activates AKT, also known as $\mathrm{PKB}$, an intracellular serine/threonine kinase. ${ }^{16}$ Activated AKT can bind and regulate many downstream effectors via its kinase activity: it phosphorylates and inhibits TSC, preventing the inhibition of $\mathrm{mTOR} .{ }^{17} \mathrm{PI} 3 \mathrm{~K}$ signaling is inhibited by the action of the PTEN that dephosphorylates PIP3, resulting in a reduced AKT activity. ${ }^{18}$ 


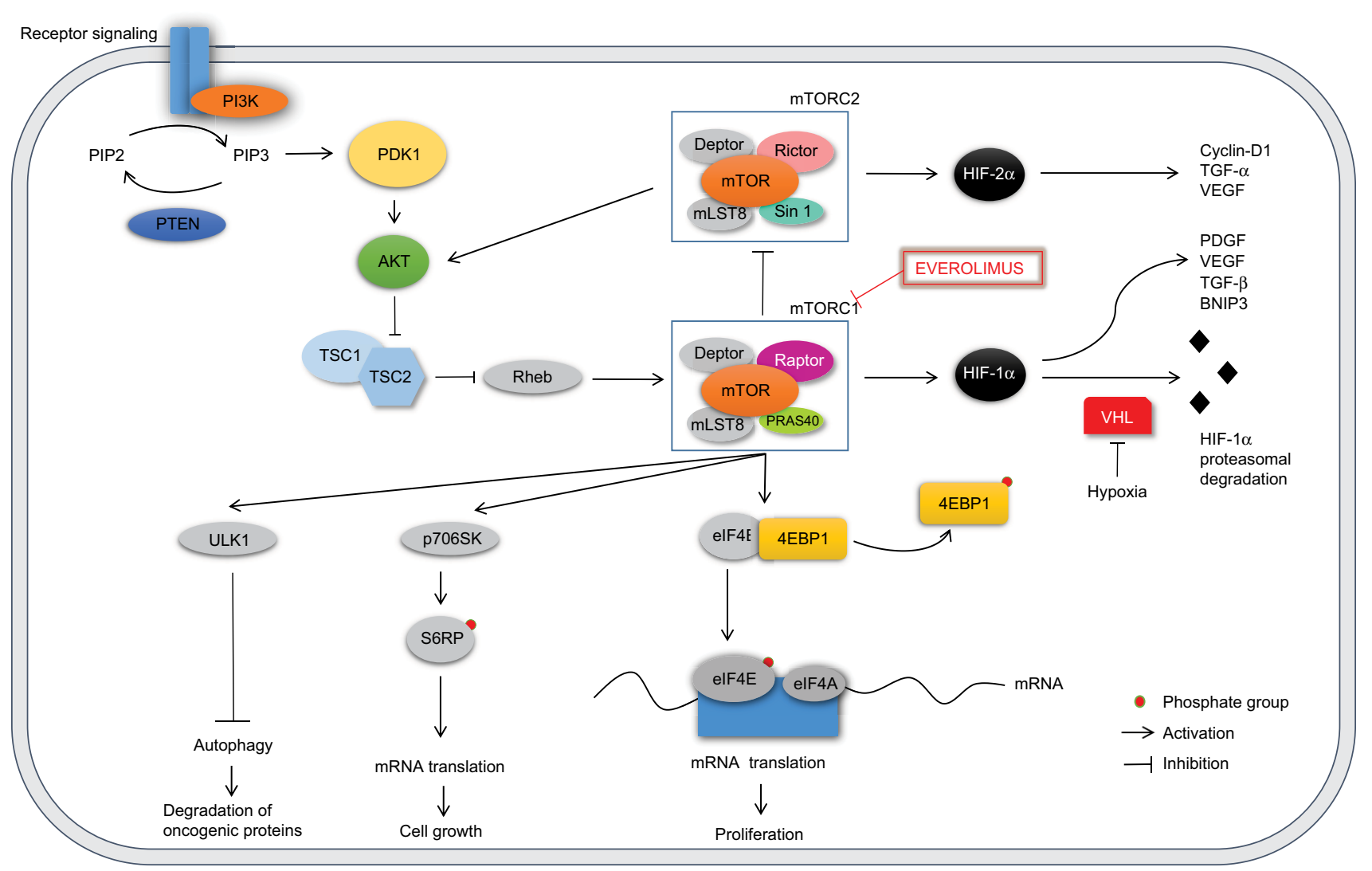

Figure I The PI3K/AKT/mTOR pathway.

Notes: PI3K mediates the conversion of PIP2 into PIP3. PIP3 regulates the membrane migration and activation of PDKI that sequentially activates AKT. PI3K is inhibited by PTEN. AKT activates mTORCI through the inhibition of TSC. mTORCI inhibits mTORC2. The two main downstream effectors of mTORCI, 4EBPI and $\mathrm{p706SK}$, regulate cell growth and proliferation. mTORCI downregulates autophagy through the activation of ULKI. HIF-I $\alpha$ increases synthesis of PDGF, VEGF, TGF- $\beta$, and BNIP3; it is degraded by VHL in normoxic condition. HIF- $2 \alpha$ increases synthesis of cyclin DI, TGF- $\alpha$, and VEGF. Everolimus inhibits mTORCI.

mTOR is a serine/threonine protein kinase involved in the regulation of various cellular functions such as growth, proliferation, and survival. ${ }^{16}$ It has been shown that mTOR takes part in the formation of two distinct multiprotein complexes: 1) mTORC1, in which mTOR is complexed with regulatory-associated protein of mTOR (Raptor), and 2) mTORC2, comprising a protein called "rapamycininsensitive companion of mTOR" (Rictor). ${ }^{19,20}$

mTORC1 promotes mRNA translation through phosphorylation of two translation regulators: 4EBP1 and S6K1/ p70S6K. ${ }^{21}$ Once phosphorylated, 4EBP1 is released from eIF4E that can interact with eIF4G and eIF4A, assembling the mammalian ribosome initiation complex at the $5^{\prime}$ end of an mRNA. Furthermore, the activated S6K1 (p-S6K1) phosphorylates the 40S S6RP, and this leads to increased translation of mRNAs. ${ }^{16}$

The result of the activation of mTORC1 downstream targets is the increased synthesis of proteins involved in the regulation of cell growth and survival, such as HIF-1 $\alpha$, FGF, VEGF, STAT3, cyclin-D, and c-Myc. ${ }^{22-24}$

The function of mTORC2 is not completely understood, but it is known to be associated with cytoskeleton organization and cell metabolism. ${ }^{21,24}$ Unlike mTORC1, mTORC2 is relatively insensitive to rapamycin, a natural antifungal antibiotic first discovered in the 1970s..$^{24,25}$ Moreover, it increases the translation of HIF-2 $\alpha$, a type of hypoxia-inducible factor more strongly implicated in RCC tumorigenesis, not regulated by mTORC1. Whereas HIF- $1 \alpha$ expression depends upon both mTORC1 and mTORC2, HIF- $2 \alpha$ is just under mTORC2 control. ${ }^{26}$ Raval et al examined the transcriptional selectivity of the HIF- $1 \alpha$ and HIF- $2 \alpha$ isoforms in VHL-defective RCC cells in vitro. This study showed unexpected suppressive interactions among the two isoforms, with enhanced expression of HIF- $2 \alpha$ suppressing HIF- $1 \alpha$ and vice versa, demonstrating that HIF- $1 \alpha$ and HIF-2 $\alpha$ have conflicting properties in the biology of RCC. In particular in a xenograft model, HIF- $1 \alpha$ was shown to delay tumor growth by stimulating the transcription of the proapoptotic gene encoding BNIP3, whereas HIF- $2 \alpha$ enhanced tumor growth through protumorigenic genes encoding cyclin-D1, TGF- $\alpha$, and VEGF. Since the study demonstrated suppressive interactions between the two isoforms of HIF, it was not clear if suppression of tumor growth by HIF-1 $\alpha$ arose from direct effects, indirect effects 
due to downregulation of HIF-2 $\alpha$, or a combination of both possibilities. $^{27}$

mTORC2 is also involved in a positive feedback loop in PI3K/AKT pathway, since it phosphorylates the serine/ threonine protein kinase AKT, one of the main upstream regulators of the signaling pathway itself. ${ }^{28}$

$\mathrm{PI} 3 \mathrm{~K} / \mathrm{AKT} / \mathrm{mTOR}$ pathway plays a central role in $\mathrm{RCC}$ tumorigenesis. Various components of this signaling cascade have been found to be overexpressed compared to normal kidneys and possibly constitutively activated in ccRCC and also in other histological subtypes. ${ }^{29}$ Expression of p-AKT, p-mTOR, and p-70S6K (isoform of S6K1) was seen in nearly $100 \%$ of both primary and metastatic RCCs (mRCCs) by immunohistochemistry, and increased proteins levels were seen in 128 primary RCCs, 22 mRCCs, and 24 normal kidneys. ${ }^{29}$ Immunohistochemical analyses were also conducted on 375 patients treated with nephrectomy for RCC: p-AKT and $\mathrm{p}-70 \mathrm{~S} 6 \mathrm{~K}$ were detected in a high percentage of cases ( $40 \%$ and $75 \%$, respectively), whereas tumors showed a lower expression of PTEN than normal renal tissues. ${ }^{30}$ Another report among $133 \mathrm{mRCC}$ samples found significantly higher immunoreactivity scores for PI3K, p-mTOR, p-AKT, and $\mathrm{p}-70 \mathrm{~S} 6 \mathrm{~K}$ in metastatic lesions compared to non-neoplastic proximal tubular epithelial cells. ${ }^{31}$

A more recent study investigated genetic alterations of 20 representative $\mathrm{PI} 3 \mathrm{~K} / \mathrm{AKT}$ pathway components in ccRCC, such as PIK3CA amplifications or mutations (5\%), PTEN deletions or mutations $(5 \%)$, or mTOR mutations $(6 \%)$, reiterating the critical role of the $\mathrm{PI} 3 \mathrm{~K} / \mathrm{AKT}$ pathway in this cancer. $^{12}$

$\mathrm{PI} 3 \mathrm{~K} / \mathrm{AKT} / \mathrm{mTOR}$ pathway is also involved in non-clear cell RCC (nccRCC) development. Activating mutations in MET gene found in type $1 \mathrm{pRCC}$ lead to the activation of the $\mathrm{PI} 3 \mathrm{~K} / \mathrm{AKT}$ pathway, resulting in increased proliferation, invasion, and metastasis. ${ }^{32}$ Mutations in FH, associated with type $2 \mathrm{pRCC}$, result in the accumulation of fumarate, which leads to the upregulation of HIF-1 $\alpha$ and activation of mTOR pathway through the mechanism described earlier. ${ }^{33}$ In addition, PTEN is the most frequently mutated or deleted component of the PI3K/AKT pathway in chRCC, as found in the latest large-scale genome-sequencing data from the literature. ${ }^{12}$

Another mechanism involved in ccRCC development and progression is mediated by mitochondrial autophagy, an adaptive metabolic response required to prevent the increase of reactive oxygen species levels and of cell death in hypoxic condition. Autophagy directly degrades oncogenic proteins to suppress tumorigenesis, as a cellular degradation process, resulting in an oncosuppressive mechanism in ccRCC. ${ }^{34}$ Whereas HIF-1 $\alpha$ promotes mitochondrial autophagy through the expression of BNIP $3,{ }^{35}$ an inhibition of autophagy results in HIF-2 $\alpha$ overexpression, which is known to have an oncogenic role in renal tumorigenesis as a transcriptional factor. ${ }^{34}$ mTOR is known to be a negative regulator of autophagy, ${ }^{36}$ and mTOR inhibition has been reported to induce autophagy. ${ }^{37}$

Eventually, considering that mTOR pathway is often activated, with a large cross talk with VHL/HIF pathway, targeting mTOR appears relevant to the antitumor effect in RCC.

\section{Everolimus}

Everolimus (RAD001, afinitor; Novartis International AG, Basel, Switzerland) is a derivate of rapamycin which inhibits the mTOR serine/threonine kinase; it differs from temsirolimus because it is not converted to rapamycin in vivo. It binds the intracellular receptor protein FKBP12 with a high affinity to form the FKBP12/everolimus complex, which specifically inhibits mTORC1. The disruption of $\mathrm{p}-\mathrm{S} 6 \mathrm{~K} 1$ and 4EBP1 function, the two main downstream effectors of mTORC1, interferes with mRNA translation of genes involved in cell cycle regulation and cellular response to hypoxia. ${ }^{38}$

Everolimus has been widely tested as an immunosuppressive agent in renal and cardiac transplant, being well tolerated and effective with daily dosing. ${ }^{39,40}$ In cancer treatment, the first preclinical data demonstrated dose-dependent antitumor activity with daily and weekly administration schedules of everolimus. Boulay et al analyzed the mTOR effectors 4EBP1 and p-S6K1 in tumor, skin, and peripheral-blood mononuclear cell (PBMC) extracts after treatment with everolimus, showing that suppression of tumor growth correlated with inactivation of $\mathrm{p}-\mathrm{S} 6 \mathrm{~K} 1$ and reduced 4EBP1 phosphorylation. This same experiment ex vivo demonstrated that 4EBP1 levels detected in PBMCs were unaffected by a suboptimal everolimus dosage, despite transient effects on p-S6K1 activity, suggesting that $\mathrm{p}-\mathrm{S} 6 \mathrm{~K} 1$ is a more sensitive marker of everolimus exposure in PBMCs than 4EBP1, making it a possible good pharmacodynamic biomarker of drug activity. ${ }^{41}$

\section{Drug formulation and dosing}

Everolimus is orally administered. Preclinical-clinical modeling studies ${ }^{42}$ and clinical pharmacodynamic studies ${ }^{43}$ suggest a daily dose of $10 \mathrm{mg}$, which achieves consistent inhibition of mTOR signaling. Weekly dose of $70 \mathrm{mg}$ did not show the same level of target inhibition as an equivalent daily dose. ${ }^{42}$

\section{Pharmacokinetics}

The peak of everolimus concentration $\left(C_{\max }\right)$ is reached from 1 to 2 hours after daily administration of $5-70 \mathrm{mg}$ under fasting conditions. In healthy subjects, high-fat meals reduced 
systemic exposure to everolimus (as measured by area under the curve, AUC) by $22 \%$; light-fat meals reduced AUC by $32 \%$. Everolimus is metabolized in the liver by cytochrome CYP3A4 and P-glycoprotein. Six main metabolites have been detected, but they showed 100 times less activity than parent drug. Data about excretion are available from transplant setting studies, since no specific excretion studies have been undertaken in cancer patients. Eighty percent of the drug is eliminated by feces, whereas $5 \%$ is excreted in the urine.

Pharmacokinetics was also investigated in special populations. The average AUC of everolimus in eight subjects with moderate hepatic impairment was double compared to AUC found in eight subjects with normal hepatic function. A 3.6-fold increase in exposure was also observed in patients with severe hepatic impairment, suggesting dose adjustments for patients with hepatic dysfunction. No significant influence of creatinine clearance and age (from 27 to 85 years) was detected in a population pharmacokinetic analysis of 170 patients with advanced solid tumors. ${ }^{44}$

\section{Clinical efficacy}

Core evidence of clinical impact of everolimus in the management of mRCC is summarized. The clinical trials of efficacy of everolimus in ccRCC are shown in Table 1, while clinical trials of efficacy of everolimus in nccRCC are shown in Table 2.

\section{Everolimus after failure of previous treatment lines}

The first evidence for the clinical efficacy of sequential therapy with everolimus for patients with metastatic ccRCC was provided by a multicenter, international, placebocontrolled Phase III trial (Renal Cell cancer treatment with Oral RAD001 given Daily [RECORD-1]), the results of which were published in 2008 by Motzer et al. Four hundred and ten patients with $\mathrm{mRCC}$ were assigned to receive either everolimus $10 \mathrm{mg}$ daily $(\mathrm{n}=272)$ or placebo $(\mathrm{n}=138)$ by $2: 1$ randomization. Of note, all patients had progressed to the previous treatment line within 6 months from the start of therapy with VEGFR-tyrosine kinase inhibitors (TKIs) (sunitinib or sorafenib, or both). Median progression-free survival (mPFS), used as primary end point, was 4.0 and 1.9 months for patients treated with everolimus and placebo, respectively (hazard ratio [HR] 0.30, 95\% confidence interval [CI] 0.22-0.40; $P<0.001)$, with no significant differences in overall survival (OS), due to the large crossover to everolimus in 112 of 139 patients $(80 \%)$ who received placebo. Benefit in progression-free survival (PFS) was seen through predefined subgroups according to the Memorial Sloan-Kettering Cancer
Center risk status, ${ }^{45}$ prior therapy, and demographic differences. ${ }^{46}$ These data provided the first evidence for the use of everolimus as a sequential therapy, supporting the inclusion of the drug in several guidelines for second-line treatment of patients with mRCC. ${ }^{47}$

The results of the RECORD-1 trial were comparable to those obtained by a Phase II study of pure second-line setting. The study showed a fairly good activity of everolimus, with an mPFS of 11.2 months, a response rate of $14 \%$, and achievement of stable disease (SD) in $73 \%$ of 39 treated patients. ${ }^{48}$

Since $26 \%$ of patients in the RECORD- 1 trial received everolimus as third-line therapy, a perspective subanalysis of this pivotal study was performed. The mPFS for everolimus given after one VEGFR-TKI was 5.4 vs 1.9 months with placebo, whereas among patients who received two previous lines of VEGFR-TKIs, mPFS was 4.0 months with everolimus and 1.8 months with placebo. These results showed that patients pretreated with a single VEGFR-TKI line had apparently longer PFS with everolimus if compared to those who received two prior lines, supporting the use of the molecule as the standard of care in patients progressive to the first VEGFR-TKI treatment. ${ }^{49}$

Afterward, in 2010, the RECORD-1 trial results were updated: mPFS for everolimus and placebo was 4.9 and 1.9 months, respectively (HR 0.33, 95\% CI 0.25-0.43; $P<0.001)$. Survival results were still confounded by the treatment crossover permitted after disease progression; an exploratory OS analysis used rank-preserving structural failure time model to correct this bias, and the corrected OS for the everolimus group was 14.8 vs 10.0 months for the placebo group..$^{50}$

The subsequent everolimus expanded access program (REACT study) enrolled 1,367 patients progressive to first-line treatment: $40 \%$ of them received everolimus after only one prior treatment line (in particular $38.5 \%$ of overall patients with a VEGFR-TKI), whereas $60 \%$ received the drug after two or more prior lines. SD was achieved in $51.6 \%$ of patients; $1.7 \%$ obtained partial response, and no complete responses were documented; $23.7 \%$ of patients had a progressive disease, and $23 \%$ were not evaluable for response. ${ }^{51}$

Very recently, two comparative head-to-head Phase III trials have been published with the aim to demonstrate the superiority of new agents vs everolimus in patients with advanced ccRCC who received one or two previous TKIs. ${ }^{52,53}$

The first study (METEOR trial) compared the efficacy of cabozantinib, a TKI targeting VEGFR, MET, and AXL proteins, and everolimus in 658 patients with RCC progressive to VEGFR-TKI therapy; PFS was the primary end point. Among the first 375 patients who underwent randomization, 73\% were treated in second-line setting, while $27 \%$ in third-line 


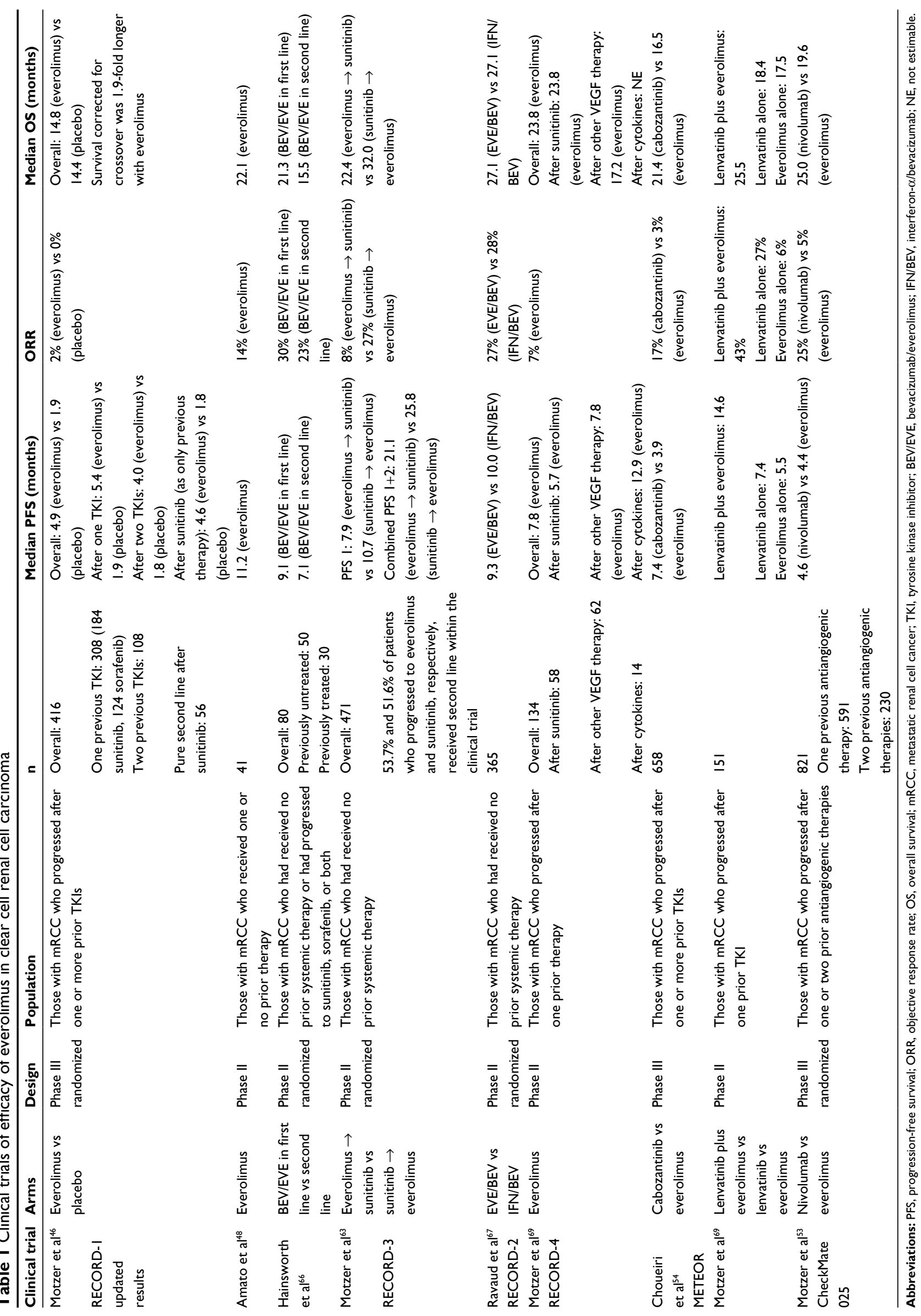


Table 2 Clinical trials of efficacy of everolimus in nccRCC

\begin{tabular}{|c|c|c|c|c|c|c|c|}
\hline Clinical trial & Arms & Design & Population & $n$ & PFS (months) & ORR (\%) & OS (months) \\
\hline Koh et $\mathrm{al}^{74}$ & Everolimus & Phase II & $\begin{array}{l}\text { Those with metastatic } \\
\text { nccRCC }\end{array}$ & 49 & $\begin{array}{l}\text { Overall: } 5.2 \\
\text { Chromophobe } \\
\text { histology: } 13.1\end{array}$ & $10 \%$ & 14.0 \\
\hline $\begin{array}{l}\text { Escudier et } \mathrm{al}^{75} \\
\text { RAPTOR }\end{array}$ & Everolimus & Phase II & $\begin{array}{l}\text { Those with metastatic } \\
\text { PRCC who had received } \\
\text { no prior systemic therapy }\end{array}$ & 92 & & & $\begin{array}{l}\text { Overall: } 21.1 \\
\text { Papillary type I: } 28.0 \\
\text { Papillary type 2: } 20.3\end{array}$ \\
\hline $\begin{array}{l}\text { Tannir et } \text { al }^{76} \\
\text { ESPN }\end{array}$ & $\begin{array}{l}\text { Sunitinib vs } \\
\text { everolimus } \\
\text { (crossover at PD) }\end{array}$ & $\begin{array}{l}\text { Phase II } \\
\text { randomized }\end{array}$ & $\begin{array}{l}\text { Those with metastatic } \\
\text { pRCC who had received } \\
\text { no prior systemic therapy }\end{array}$ & 68 & $\begin{array}{l}\text { In first line: } \\
6.1 \text { (sunitinib) vs } \\
4.1 \text { (everolimus) } \\
\text { In second line: } \\
1.8 \text { (sunitinib) vs } \\
2.8 \text { (everolimus) }\end{array}$ & $\begin{array}{l}\text { In first line: } \\
9 \% \text { (sunitinib) vs } \\
2 \% \text { (everolimus) } \\
\text { In second line: } \\
9.5 \% \text { (sunitinib) vs } \\
8.6 \% \text { (everolimus) }\end{array}$ & $\begin{array}{l}16.2 \text { (sunitinib) vs } \\
\text { I4.9 (everolimus) }\end{array}$ \\
\hline $\begin{array}{l}\text { Armstrong } \\
\text { et } \mathrm{al}^{77} \\
\text { ASPEN }\end{array}$ & $\begin{array}{l}\text { Everolimus vs } \\
\text { sunitinib }\end{array}$ & $\begin{array}{l}\text { Phase II } \\
\text { randomized }\end{array}$ & $\begin{array}{l}\text { Those with metastatic } \\
\text { pRCC who had received } \\
\text { no prior systemic therapy }\end{array}$ & 108 & $\begin{array}{l}\text { Overall: } 5.6 \\
\text { (everolimus) vs } \\
8.3 \text { (sunitinib) } \\
\text { chRCC: } 11.4 \\
\text { (everolimus) vs } \\
5.5 \text { (sunitinib) } \\
\text { pRCC: } 5.5 \\
\text { (everolimus) vs } \\
8.1 \text { (sunitinib) }\end{array}$ & $\begin{array}{l}5 \% \text { (everolimus) vs } \\
4 \% \text { (sunitinib) }\end{array}$ & $\begin{array}{l}\text { I3.2 (everolimus) vs } \\
31.5 \text { (sunitinib) }\end{array}$ \\
\hline
\end{tabular}

Abbreviations: nccRCC, non-clear cell renal cell cancer; PFS, progression-free survival; ORR, objective response rate; OS, overall survival; pRCC, papillary renal cell carcinoma; PD, progressive disease; chRCC, chromophobe renal cell cancer.

setting. The obtained results were in favor of cabozantinib: the very recently updated reports of METEOR trial results evidenced a final PFS across all the 658 enrolled patients of 7.4 months for cabozantinib compared to 3.9 months for everolimus (HR $0.51,95 \%$ CI $0.41-0.62 ; P<0.0001$ ) and an improved objective response rate (ORR) of $17 \%$ with cabozantinib vs $3 \%$ for everolimus $(P<0.0001)$. Moreover, a highly statistically significant and clinically meaningful increase in OS was demonstrated for patients who received cabozantinib compared to everolimus in a second interim analysis for OS of this pivotal Phase III study, reaching an OS of 21.4 months in the experimental arm vs 16.5 months for everolimus (HR 0.66, 95\% CI 0.53-0.83; $P=0.00026$ ) ${ }^{54}$ Subgroup analyses presented at the American Society of Clinical Oncology 2016 Annual Meeting showed that PFS benefit of cabozantinib was obtained in all subgroups of patients defined by prior number and type of TKIs and by the site of metastases (bone and visceral). ${ }^{55,56}$

The second study (CheckMate 025) compared nivolumab, a PD-1 immune checkpoint inhibitor, to everolimus in an overall population of 821 patients with advanced ccRCC pretreated with one or two antiangiogenic therapies, with OS as primary end point. Seventy-eight percent of patients were treated in second line, while $22 \%$ in third line. Results showed a median overall survival (mOS) improvement in patients who received nivolumab compared to those treated with everolimus (25.0 vs 19.6 months; HR $0.73,98.5 \%$
CI $0.57-0.93 ; P=0.002)$ with no significant differences in terms of mPFS (4.6 months for nivolumab vs 4.4 months for everolimus; HR $0.88,95 \%$ CI $0.75-1.03 ; P=0.11$ ). This could imply that nivolumab may improve overall responses without obtaining an advantage in terms of PFS compared to everolimus. ${ }^{53}$ Of note, the mOS obtained with everolimus was better than expected in comparison with RECORD-1 trial, in which mOS for everolimus was 14.8 months; this could be due to a different selection of patients. Moreover, it is interesting to observe that Motzer et al used the modified Memorial Sloan-Kettering Cancer Center prognostic score with three parameters for stratification ${ }^{45}$ instead of the original five parameters score ${ }^{57}$ or the more recently validated International Metastatic Renal Cell Carcinoma Database Consortium model by Heng et al. ${ }^{58}$ This particular choice could have influenced the expected results in the different subgroups.

In conclusion, both studies demonstrated an advantage in terms of PFS and/or OS for the comparator with respect to everolimus after failure of previous TKI therapies, affording the change of the clinical practice in the next future.

In the light of these recent studies, the role of everolimus in RCC will be undoubtedly shifted to the third or subsequent treatment lines. Nevertheless, neither retrospective nor prospective data have been yet provided about the best therapeutic option after progression to second-line immune checkpoint blockade. Despite the temptation of simply 
shifting the therapeutic sequence, a careful reflection should be dedicated to the issue of suppressing the immune system with everolimus after treatment with an immunostimulating agent such as nivolumab, considering that the opposite effects of such drugs could potentially be counterproductive both on the patient and on the tumor microenvironment.

\section{Indirect comparisons of everolimus efficacy in second-line setting}

In December 2011, Rini et $\mathrm{al}^{59}$ reported the results of a Phase III trial (AXIS study) comparing two alternative second-line therapies after failure of a single first-line treatment, obtaining an mPFS of 6.7 months with axitinib compared to 4.7 months with sorafenib (HR 0.665, 95\% CI 0.544-0.812; one-sided $P<0.0001)$. These findings raised some questions about the role of everolimus in this context, especially considering the design of the study, in which the sequencing was specifically defined as second line, differently from RECORD-1 study which included also subsequent lines. Furthermore, in the AXIS study, the majority of patients (54\%) received first-line sunitinib, which is one of the standards of care in clinical practice, ${ }^{1}$ whereas the previous treatments in the RECORD-1 study were disparate.

The lack of data regarding head-to-head comparisons of everolimus with other drugs currently approved in secondline setting (ie, axitinib and sorafenib) for the management of advanced RCC raised the need of more in-depth analysis of the topic.

Two recent meta-analyses with indirect treatment comparisons ${ }^{60,61}$ have been published with the aim to compare the outcomes among the new targeted agents for pretreated mRCC. With the limits of cross-trial statistical comparisons, data were inconclusive to demonstrate a significant difference in terms of PFS of everolimus vs axitinib or sorafenib, respectively.

\section{Everolimus in a pure second-line setting: RECORD-4 study}

Recently, Motzer et al investigated the clinical efficacy of everolimus in a pure second-line setting. Thus, 134 patients were enrolled in a Phase II prospective trial; 58 patients previously received sunitinib, 62 patients received other VEGFR-TKIs, and 14 patients were previously treated with cytokines. mPFS with everolimus was 5.7, 7.8, and 12.9 months, respectively, for the three cohorts. Overall, $67 \%$ of patients achieved SD as their best objective response. These data confirm the benefit in terms of PFS of second-line everolimus in mRCC patients. ${ }^{62}$

\section{Everolimus in first-line setting}

A Phase II, non-inferiority, randomized trial explored efficacy and safety of first-line treatment with everolimus followed by second-line sunitinib, compared to the standard sequence with sunitinib followed by everolimus in the setting of mRCC, assessing PFS non-inferiority as primary end point. Four hundred and seventy-one patients were randomized to receive one of the two sequences, and the combined mPFS was 21.1 months for the everolimus-sunitinib vs 25.8 months for the sunitinib-everolimus arm (HR 1.3, 95\% CI 0.9-1.7). Since the primary end point was not met, the trial results supported the standard treatment paradigm of first-line sunitinib followed by everolimus at disease progression. ${ }^{63}$

This standard sequence is also supported by the results of a more recent Phase II trial investigating the efficacy of planned alternation of sunitinib and everolimus as first line in 55 patients affected by mRCC. The study treatment consisted of 6-week subcycles of sunitinib $50 \mathrm{mg}$ once daily for 4 weeks followed by 2 -week rest, with a subsequent 6-week subcycle of everolimus $10 \mathrm{mg}$ once daily for 5 weeks followed by 1 -week rest, for a total of 12 weeks. The primary end point was the status of being both alive and progression free at month 6 , and the high level of efficacy for the schedule was set at a PFS at 6 months $\geq 84 \%$. The primary end point was not met since 29 of the 55 assessable participants $(53 \%, 95 \%$ CI $40 \%-66 \%)$ were alive and not progressive at 6 months. ${ }^{64}$

\section{Everolimus in combination therapy}

Combination therapy is generally associated with better responses but higher toxicity in medical oncology, and it has also been a challenge for $\mathrm{mRCC}$. The rationale of associating two different agents in the treatment of RCC results from the notion that blocking the VEGF pathway can lead to hypoxia, and inhibiting the mTOR response to hypoxia may block the cellular response to the hypoxic stress. ${ }^{65}$ Starting from this premise, a Phase II study was conducted on 50 previously untreated and 30 pretreated patients with $\mathrm{mRCC}$. The patients received bevacizumab, a anti-circulating VEGF antibody, and everolimus as first- and second-line therapy, respectively, and showed an mPFS of 9.1 months for first-line therapy and 7.1 months for second-line therapy. ${ }^{66}$

A subsequent large Phase II trial compared everolimus plus bevacizumab (EVE/BEV) to bevacizumab and interferon- $\alpha 2 \mathrm{a}$ in $365 \mathrm{mRCC}$ patients previously untreated (RECORD-2 study). The combination EVE/BEV in first line led to a PFS of 9.3 vs 10.0 months of bevacizumab and interferon- $\alpha 2 \mathrm{a}$ (HR $0.91,95 \%$ CI $0.69-1.19 ; P=0.485$ ); 
ORRs were $27 \%$ vs $28 \%$, respectively, demonstrating a similar efficacy for the two combination regimens. ${ }^{67}$

A Phase III trial comparing the use of the combination $\mathrm{EVE} / \mathrm{BEV}$ to everolimus alone in second-line setting after failure of sunitinib is currently ongoing (NCT01198158).

The approach of combined strategy blocking both the VEGF and PI3K/AKT/mTOR cascade has been assessed in a Phase I study that investigated the safety and efficacy of everolimus plus pazopanib in refractory solid tumors with molecular alterations in the PI3K/AKT/mTOR pathway, such as PI3K mutation and PTEN loss. The treatment seemed to be well tolerated and demonstrated a certain activity in refractory solid tumors. ${ }^{68}$

More recently, Motzer et al investigated the use of everolimus in combination with a novel TKI, lenvatinib, in a randomized three-arm Phase II study, restoring hopes on synergistic combination therapy. One hundred and fifty-three enrolled patients progressive to first-line VEGFR-TKI were randomly assigned to receive lenvatinib plus everolimus, single-agent lenvatinib, or single-agent everolimus. The combination therapy significantly prolonged mPFS compared to the single-agent everolimus or lenvatinib (14.6 vs 5.5 and 7.4 months, respectively), and ORR was significantly higher for the combination vs single agent ( $43 \%$ vs $6 \%$ and $27 \%$ for everolimus and lenvatinib, respectively). Moreover, a trend for the combination advantage was also suggested in terms of OS: mOS was 25.5 months for lenvatinib plus everolimus, 18.4 months for single-agent lenvatinib, 17.5 months for single-agent everolimus (HR 0.55, 95\% CI 0.3-1.01; $P=0.062$ for lenvatinib plus everolimus vs single-agent everolimus; and HR $0.74,95 \%$ CI $0.4-1.36 ; P=0.3$ for lenvatinib plus everolimus vs single-agent lenvatinib). The difference in mOS between patients receiving the combination and those treated with everolimus alone was even higher in the post hoc updated analysis, finally reaching statistical significance (25.5 vs 15.4 months; HR $0.51,95 \%$ CI $0.30-0.88 ; P=0.024)$. However, the combination treatment seemed to be more toxic than single-agent everolimus; grade 3-4 (G3-4) serious adverse events (AEs) occurred in $71 \%$ of patients who received the combination regimen vs $50 \%$ for everolimus alone. ${ }^{69}$

These promising data suggest that maintaining the suppression of VEGF pathway in synergic combination with the inhibition of a main molecular target such as mTOR could represent a good strategy after progression to the first-line VEGFR TKI, even if Phase III studies are needed to confirm this statement.

An interesting Phase II first-line trial by Broom et al evaluated the effect of everolimus alone compared with everolimus plus zoledronic acid on bone metastases from
RCC. The primary outcome measure was uNTX level, a measure of bone resorption and a biomarker of effectiveness of bone-specific therapies. Interestingly, a decrease of uNTX level was seen in all patients treated with everolimus plus zoledronic acid over 12 weeks of therapy but not in the cohort of patients treated with everolimus alone. The reduction in mean UNTX on everolimus plus zoledronic acid compared to everolimus alone was $68.3 \%(P<0.0001)$. These results indicate that the addition of zoledronic acid may inhibit tumor-induced osteoclast activity more effectively than everolimus alone. A benefit in PFS was also seen by adding zoledronic acid (7.5 months for everolimus plus zoledronic acid vs 5.4 months for everolimus alone, $P=0.009$ ), implying that the addition of bisphosphonates to everolimus in patients with bone metastases from RCC may prolong the tumor control. ${ }^{70}$

\section{Everolimus in nccRCC}

Among nccRCCs, pRCC subtype accounts from 7\% to $15 \%$ of renal cell cancers. Benefits of mTOR inhibition seem to be greater in pRCC than in clear cell subtype, and this could be explained by the upregulation of HIF and products of target genes noticed in this histologic subtype associated with $\mathrm{FH}$ mutations. ${ }^{33}$ In support to this hypothesis, a large Phase III trial explored the efficacy of temsirolimus, an mTOR inhibitor, in 626 patients with previously untreated poor-prognosis mRCC: in this study, temsirolimus showed a better outcome compared to IFN in patients with non-clear cell histotype $(n=73)$. Of note, patients were not stratified by histology. ${ }^{71}$ Nevertheless, it is not clear if this apparent benefit could be ascribed to a real efficacy of mTOR inhibitor or rather to a detrimental effect of interferon- $\alpha$ (IFN) in this population. ${ }^{72}$ Based on these observations, a single-arm Phase II trial with everolimus in nccRCC patients was started. Forty-nine patients were enrolled, and 59.2\% had papillary histology. Everolimus was given as first-line (53.1\%) or second-line therapy (46.9\%): mPFS was 3.7 months for previously untreated patients and 5.3 months for patients who progressed after prior sunitinib or sorafenib. Interestingly, patients with chromophobe histology tended to have longer PFS than those with other nccRCC subtypes ( 13.1 vs 3.4 months, $P=0.084$ ). ${ }^{73}$

In a post hoc subgroup analysis of metastatic nccRCC patients $(n=66)$ enrolled in the RECORD-3 trial, mPFS was shorter for patients treated with everolimus compared to those treated with sunitinib in first-line setting (5.1 vs 7.2 months; HR 1.5, 95\% CI 0.9-2.8). ${ }^{63}$

The following Phase II RAPTOR trial investigated the activity and safety of everolimus as first-line therapy for metastatic pRCC. The mOS for 92 patients was 21.1 months; the 
mOS for papillary types 1 and 2 was 28.0 and 20.3 months, respectively. ${ }^{74}$

More recently, two Phase II randomized trials were conducted to investigate efficacy of everolimus in first-line setting in patients with nccRCC. The first study (ESPN) compared the efficacy of the sequential therapy everolimus-sunitinib vs sunitinib followed by everolimus in patients with metastatic nccRCC. Primary end point was PFS in first-line therapy. In 68 patients, the mPFS for everolimus was 4.1 months when administered in first line, while it was 2.8 months in second line. The mPFS for first-line sunitinib was 6.1 months, and 1.8 months if given in second line. Since the primary end point was not reached, the trial was closed early. The mOS registered for first-line everolimus (10.5 months) was inferior to the OS for first-line sunitinib; at final analysis, mOS was 16.2 months for sunitinib-everolimus sequence and 14.9 months for everolimus-sunitinib $(P=0.18){ }^{75}$

The second study (ASPEN) compared everolimus and sunitinib in previously untreated patients with non-clear cell histology. The results showed an mPFS of 5.6 months for everolimus and 8.3 months for sunitinib (HR 1.41, $80 \%$ CI $1.03-1.92 ; P=0.16)$; mOS was not statistically different between the two treatment groups and was 13.2 vs 31.5 months, respectively (HR $1.12,95 \%$ CI $0.7-2.1 ; P=0.60$ ). Of note, crossover at progression of disease was not previously established, even if it occurred in $22 \%$ of patients receiving sunitinib and in $18 \%$ of patients receiving everolimus. The patients were also stratified according to the histological subtypes, and everolimus seemed to have better activity in chRCC, with an mPFS of 11.4 vs 5.5 months of sunitinib. Contrariwise, sunitinib seemed to be more efficient in patients with papillary histotype (mPFS: 8.1 vs 5.5 months). ${ }^{76}$ However, these results should be handled with care due to the heterogeneous population, small sample size, and imbalance in patients' characteristics. ${ }^{72}$

According to this evidence, everolimus is not recommended as first-line therapy in patients affected by metastatic nccRCC, whereas it finds a place in second-line setting after progression to previous sunitinib.

\section{Predictive biomarkers}

The identification of predictive biomarkers for response to mTOR inhibitors and the definition of their possible prognostic value has been a challenge since the advent of these new targeted therapies. Various studies identified the overexpression of phosphorylated proteins, such as p-mTOR, p-AKT, p-70S6K, and p-4EBP1, in patients with RCC; ${ }^{29-31}$ moreover, phosphorylated forms of S6RP (p-S6RP) and p-4EBP1 are often employed as an immunohistochemical measure of mTOR activity. A large study on 419 ccRCC patients including all stages of disease demonstrated that the cumulative number of altered biomarkers in mTOR pathway is an independent predictor of the clinical outcome, underlying that examining multiple markers together could improve their potential predictive value for response to targeted therapies with mTOR inhibitors. ${ }^{77}$

The first investigations were conducted on RCC samples of patients treated with temsirolimus: on 20 samples collected from the renal primary tumor $(60 \%)$ and from metastatic lesions $(40 \%)$ before the starting of the treatment, a positive association between $\mathrm{p}-\mathrm{S} 6 \mathrm{RP}$ expression and clinical response to temsirolimus was found, whereas low expression of p-S6RP correlated with progressive disease. ${ }^{78}$ After TKI failure in Chinese RCC patients, a Phase Ib trial of everolimus explored the expression of $\mathrm{p}-\mathrm{AKT}$, p-mTOR, p-4EBP1, and p-S6RP by immunohistochemistry in paraffin-embedded tumor tissue specimens derived from $18 \mathrm{RCC}$ patients. In this study, patients with the expression of p-mTOR or p-S6RP on the primary tumor had longer mPFS compared to patients with no expression ( 11.3 vs 3.7 months for $\mathrm{p}-\mathrm{mTOR}, P=0.001 ; 11.3$ vs 3.7 months for $\mathrm{p}-\mathrm{S} 6 \mathrm{RP}, P=0.002$ ); co-expression of these two targets with p-4EBP1 was also associated with a longer PFS. Moreover, none of the patients without expression of p-mTOR or p-S6RP experienced benefits with everolimus. According to the results of this study, it could be supposed that expression status of p-mTOR and p-S6RP (that could imply a hyperactivation of mTOR pathway) may be applied as a potential predictive biomarker for everolimus efficacy in patients with $\mathrm{mRCC}$, and a potential indicator for selection of patients. ${ }^{79}$ However, these data may have been confounded by a bias, since the detection of p-mTOR and p-S6RP has been assessed on tissue available after nephrectomy at baseline, before TKI treatment, and not just before everolimus therapy.

A more recent study by Knoll et al explored the role of p-S6RP, the major mediator of antitumoral effects exerted by everolimus, in vitro and in a novel ex vivo tissue slice model using fresh vital human RCC tissue, and then incubating the tissue with everolimus. While mTOR and S6RP were expressed in all tested cell lines, and their level was not substantially altered by everolimus, the phosphorylation of S6RP was completely blocked by the drug, due to its inhibitory effect on activation of mTOR pathway. As a next step, the investigators explored the effects of everolimus on proliferation and protein synthesis, silencing the expression of S6RP with a small interfering RNA and subsequently treating RCC cells with the drug. Interestingly, the downregulation of S6RP completely abolished the everolimus inhibitory effect on protein synthesis and cell proliferation, 
suggesting that S6RP is crucial for everolimus activity and may be considered as a predictive biomarker. ${ }^{80}$

Until now, there is no prospectively validated predictive biomarker to monitor everolimus response or to apply a useful selection of patient candidate to mTOR inhibition; S6RP, a main downstream effector of the cascade, and its phosphorylated form $\mathrm{p}$-S6RP are promising for this role, but their clinical use should be further validated.

\section{Safety}

Several class-specific AEs can occur with everolimus treatment, such as hyperglycemia, alterations of lipid metabolism, and nonspecific interstitial pneumonitis. According to the RECORD-1 study, the most relevant clinical AEs of every grade in patients treated with everolimus for $\mathrm{mRCC}$ were stomatitis (40\%), rash (25\%), fatigue (20\%), asthenia (18\%), diarrhea $(17 \%)$, anorexia $(16 \%)$, nausea $(15 \%)$, and pneumonitis $(14 \%)$. Of these, stomatitis (3\%) and fatigue $(3 \%)$ were the most common toxicities of G3-4. Other relevant complications included G3-4 infections (3\%) and G3-4 pneumonitis (3\%). The most frequent laboratory abnormalities of any grade were anemia (91\%), hypercholesterolemia (76\%), hypertriglyceridemia (71\%), and hyperglycemia (50\%); lymphopenia (16\%), hyperglycemia (12\%), and anemia (10\%) mostly occurred as G3-4 toxicities. Of note, deaths occurred in 14 patients receiving everolimus $(5 \%)$ within 28 days of their last dose, and one death was caused by overwhelming Candida sepsis, complicated by acute respiratory failure. ${ }^{46}$

The same toxicity profile was confirmed in more recent studies. In METEOR and CheckMate 025 trials, the wellknown toxicity profile of the molecule was furthermore confirmed. Higher-than-expected toxicity was instead reported for everolimus in the METEOR trial, with G3-4 AEs in 58\% of cases: this could be partially explained by the fact that the authors of this study quoted all toxicities among events and not only treatment-related AEs. ${ }^{52,53}$

mTOR pathway has been implicated in insulin resistance: ${ }^{81}$ mTOR inhibitors are known to be associated with hyperglycemia because of their effects on inhibition of glucose uptake and insulin synthesis. ${ }^{82}$ Moreover, inhibition of mTOR interferes with cell metabolism, leading to dyslipidemia. ${ }^{21}$ No official guidelines on the management of hyperglycemia and hyperlipidemia associated with everolimus are available, but physicians should consider an adequate glucose and lipids control before initiation of the treatment, intermittent monitoring of fasting glucose levels, and a strict control of laboratory parameters. ${ }^{83}$ Some HMG-CoA reductase inhibitors can also be coadministered with everolimus for the treatment of hyperlipidemia, with no significant pharmacokinetic interferences. ${ }^{84}$

It is important to consider that interstitial pneumonitis also represents a noteworthy complication that can lead to differential diagnosis troubles. It is often asymptomatic, or it could appear with dyspnea and/or cough as a late complication. This AE has been investigated in a substudy of the RECORD-1 pivotal trial: among 274 patients enrolled to receive everolimus, 20 cases required dose reduction due to pneumonitis, and ten permanently discontinued treatment, whereas 54\% of clinical pneumonitis (20/37) cases were reversible. Based on radiological features and clinical implications, the authors issued guidelines for specific management of this particular AE. ${ }^{85}$

\section{Quality of life}

Changes in patient's quality of life (QoL) with everolimus treatment have been investigated in the RECORD-1 Phase III trial. QoL was assessed with the European Organization for Research and Treatment of Cancer Quality of Life Questionnaire $^{86}$ and with the Functional Assessment of Cancer Therapy Kidney Symptom Index-Disease-Related Symptoms $;{ }^{87}$ both questionnaires were administered before and after treatment with everolimus or placebo. In the study, a trend towards a detrimental effect on physical functioning or global QoL for everolimus arm was evidenced. ${ }^{88}$

\section{Cost-effectiveness}

Cost-effectiveness analysis (CEA) for everolimus has been performed to better understand the budget impact of this targeted drug; outputs were expressed as incremental costeffectiveness ratio (ICER) and cost per quality-adjusted life-year (QALY). CEA was assessed in the UK after the introduction of everolimus for the treatment of $\mathrm{mRCC}$ and was compared to the best supportive care (BSC) alone for the treatment of $\mathrm{mRCC}$ in second line: the new targeted drug was not found to be cost-effective compared to BSC, with a basecase ICER of $£ 61,330$ and an estimated ICER of $£ 76,070$ / QALY for everolimus vs BSC. The gain in QALYs was estimated to be 0.304 (0.607 QALYs for BSC plus everolimus vs 0.302 QALYs for BSC plus placebo). ${ }^{89}$ A subsequent CEA conducted in the US examined the cost-effectiveness of everolimus vs sorafenib in $\mathrm{mRCC}$ patients after prior sunitinib failure, and found that everolimus is likely to be cost-effective when compared to sorafenib treatment in this setting of patients (ICER: \$89,160/QALY), with a gain in QALYs over sorafenib of $0.916 .{ }^{90}$ Mihajlovic et al conducted a CEA in Serbia, comparing everolimus treatment to BSC in patients refractory to sunitinib, and estimated an ICER of 
$€ 87,000 / \mathrm{QALY}$. Based on this analysis, everolimus seemed to be a costly therapeutic alternative to BSC in Serbia but with a relatively small budgetary impact. ${ }^{91}$

After the advent of axitinib for the treatment of $\mathrm{mRCC}$ patients in second-line setting, a CEA was performed on results of two indirect comparisons of outcomes of everolimus vs axitinib from a US payer's perspective. ${ }^{55,92}$ Patients treated with everolimus reached an average lifetime cost of $\$ 104,226$ vs $\$ 117,211$ for patients treated with axitinib, with a difference of $\$ 12,985$ in favor of everolimus, largely due to the difference in drug costs. Following sensitivity analyses consistently demonstrated that everolimus remains a less costly therapeutic option than axitinib for treating patients with advanced RCC after failure of standard sunitinib. ${ }^{93}$

Finally, a recent review dealing with pharmacoeconomic and clinical implications of sequential therapy for $\mathrm{mRCC}$ patients in Central and Eastern Europe examined availability and reimbursement of drugs for treatment of $\mathrm{mRCC}$ up to 2016, showing large access within all Central and Eastern European countries to the standard second-line drugs, including everolimus, despite various restrictions on reimbursement, including those based on duration and choice of previous treatment, for example, in Bosnia and Herzegovina, Latvia, and Serbia. ${ }^{94}$

\section{Conclusion}

Everolimus still represents the current standard of treatment for RCC progressive to previous treatment lines with VEGFR-TKI. Its efficacy is maintained independently from the histology, both in clear cell and non-clear cell carcinoma; among nccRCCs, it seems to have a stronger activity on chRCC. Its use in first-line setting, alone or in combination with bevacizumab, is not supported by clinical trials. On the basis of recent evidence, everolimus efficacy could be predicted by immunohistochemical measurements of S6RP and its phosphorylated form, as positive predictive biomarkers of response. The safety of everolimus is widely demonstrated, with an acceptable rate of AEs.

The evidence about two new molecules, cabozantinib and nivolumab, successfully tested head-to-head with everolimus in recently published Phase III trials, will determine the shift of the drug to the third-line setting and subsequent lines of treatment. Promising data for its association with lenvatinib probably support the opportunity of everolimus to still remain in second-line setting for RCC treatment.

\section{Disclosure}

The authors report no conflicts of interest in this work.

\section{References}

1. Escudier B, Porta C, Schmidinger M, et al. Renal cell carcinoma: ESMO Clinical Practice Guidelines for diagnosis, treatment and follow-up. Ann Oncol. 2014;25(Suppl 3):iii49-iii56.

2. Hickey MM, Simon MC. Regulation of angiogenesis by hypoxia and hypoxia-inducible factors. Curr Top Dev Biol. 2006;76:217-257.

3. Banumathy G, Cairns P. Signalling pathways in renal cell carcinoma. Cancer Biol Ther. 2010;10(7):658-664.

4. Young AC, Craven RA, Cohen D, et al. Analysis of $V H L$ gene alterations and their relationship to clinical parameters in sporadic conventional renal cell carcinoma. Clin Cancer Res. 2009;15(24):7582-7592.

5. Frew IJ, Moch H. A clearer view of the molecular complexity of clear cell renal cell carcinoma. Annu Rev Pathol. 2015;10:263-289.

6. Robb VA, Karbowniczek M, Klein-Szanto AJ, Henske EP. Activation of the mTOR signalling pathway in renal clear cell carcinoma. $J$ Urol. 2007;177(1):346-352.

7. Wysocki PJ. mTOR in renal cell cancer: modulator of tumor biology and therapeutic target. Expert Rev Mol Diagn. 2009;9(3):231-241.

8. Kruck S, Bedke J, Hennenlotter J, et al. Activation of mTOR in renal cell carcinoma is due to increased phosphorylation rather than protein overexpression. Oncol Rep. 2010;23(1):159-163.

9. Milella M, Felici A. Biology of metastatic renal cell carcinoma. J Cancer. 2011;2:369-373.

10. Bernardi R, Guernah I, Jin D, et al. PML inhibits HIF-1 $\alpha$ translation and neoangiogenesis through repression of mTOR. Nature. 2006;442(7104): 779-785.

11. Toschi A, Lee E, Gadir N, Ohh M, Foster DA. Differential dependence of hypoxia-inducible factors $1 \alpha$ and $2 \alpha$ on mTORC1 and mTORC2. J Biol Chem. 2008;283(50):34495-34499.

12. Guo H, German P, Bai S, et al. The PI3K/AKT pathway and renal cell carcinoma. J Genet Genomics. 2015;42(7):343-353.

13. Katso R, Okkenhaug K, Ahmadi K, White S, Timms J, Waterfield MD. Cellular function of phosphoinositide 3-kinases: implications for development, immunity, homeostasis, and cancer. Annu Rev Cell Dev Biol. 2001;17:615-675.

14. Leevers SJ, Vanhaesebroeck B, Waterfield MD. Signalling through phosphoinositide 3-kinases: the lipids take centre stage. Curr Opin Cell Biol. 1999;11(2):219-225.

15. Kodaki T, Woscholski R, Hallberg B, Rodriguez-Viciana P, Downward J, Parker PJ. The activation of phosphatidylinositol 3-kinase by Ras. Curr Biol. 1994;4(9):798-806.

16. Hay N, Sonenberg N. Upstream and downstream of mTOR. Genes Dev. 2004;18(16):1926-1945.

17. Manning BD, Cantley LC. AKT/PKB signalling: navigating downstream. Cell. 2007;129(7):1261-1274.

18. Sansal I, Sellers WR. The biology and clinical relevance of the PTEN tumor suppressor pathway. J Clin Oncol. 2004;22(14):2954-2963.

19. Kim DH, Sarbassov DD, Ali SM, et al. mTOR interacts with raptor to form a nutrient-sensitive complex that signals to the cell growth machinery. Cell. 2002;110(2):163-175.

20. Sarbassov DD, Ali SM, Kim DH, et al. Rictor, a novel binding partner of $\mathrm{mTOR}$, defines a rapamycin-insensitive and raptor-independent pathway that regulates the cytoskeleton. Curr Biol. 2004;14(14):1296-1302.

21. Wullschleger $\mathrm{S}$, Loewith $\mathrm{R}$, Hall MN. TOR signalling in growth and metabolism. Cell. 2006;124(3):471-484.

22. Hudes GR. Targeting mTOR in renal cell carcinoma. Cancer. 2009;115(10 Suppl):2313-2320.

23. Azim H, Azim HA Jr, Escudier B. Targeting mTOR in cancer: renal cell is just a beginning. Target Oncol. 2010;5(4):269-280.

24. Guertin DA, Sabatini DM. Defining the role of mTOR in cancer. Cancer Cell. 2007;12(1):9-22.

25. Sehgal SN, Baker H, Vezina C. Rapamycin (AY-22,989), a new antifungal antibiotic. II. Fermentation, isolation and characterization. JAntibiot. 1975;28(10):727-732.

26. Toschi A, Lee E, Gadir N, Ohh M, Foster DA. Differential dependence of hypoxia-inducible factors 1 alpha and 2 alpha on mTORC1 and mTORC2. J Biol Chem. 2008;283(50):34495-34499. 
27. Raval RR, Lau KW, Tran MG, et al. Contrasting properties of hypoxiainducible factor 1 (HIF-1) and HIF-2 in von Hippel-Lindau-associated renal cell carcinoma. Mol Cell Biol. 2005;25(13):5675-5686.

28. Sarbassov DD, Guertin DA, Ali SM, Sabatini DM. Phosphorylation and regulation of Akt/PKB by the rictor-mTOR complex. Science. 2005; 307(5712):1098-1101.

29. Lin F, Zhang PL, Yang XJ, Prichard JW, Lun M, Brown RE. Morphoproteomic and molecular concomitants of an overexpressed and activated mTOR pathway in renal cell carcinomas. Ann Clin Lab Sci. 2006;36(3): 283-293.

30. Pantuck AJ, Seligson DB, Klatte T, et al. Prognostic relevance of the mTOR pathway in renal cell carcinoma: implications for molecular patient selection for targeted therapy. Cancer. 2007;109(11):2257-2267.

31. Abou Youssif T, Fahmy MA, Koumakpayi IH, et al. The mammalian target of rapamycin pathway is widely activated without PTEN deletion in renal cell carcinoma metastases. Cancer. 2011;117(2):290-300.

32. Twardowski PW, Mack PC, Lara PN Jr. Papillary renal cell carcinoma: current progress and future directions. Clin Genitourin Cancer. 2014; 12(2):74-79.

33. Isaacs JS, Jung YJ, Mole DR, et al. HIF overexpression correlates with biallelic loss of fumarate hydratase in renal cancer: novel role of fumarate in regulation of HIF stability. Cancer Cell. 2005;8(2):143-153.

34. Liu XD, Yao J, Tripathi DN, et al. Autophagy mediates HIF $2 \alpha$ degradation and suppresses renal tumorigenesis. Oncogene. 2015;34(19): 2450-2460.

35. Zhang H, Bosch-Marce M, Shimoda LA, et al. Mitochondrial autophagy is an HIF-1-dependent adaptive metabolic response to hypoxia. $J$ Biol Chem. 2008;283(16):10892-10903.

36. Kim J, Kundu M, Viollet B, Guan KL. AMPK and mTOR regulate autophagy through direct phosphorylation of Ulk1. Nat Cell Biol. 2011; 13(2):132-141.

37. He C, Klionsky DJ. Regulation mechanisms and signaling pathways of autophagy. Annu Rev Genet. 2009;43:67-93.

38. Gingras AC, Raught B, Sonenberg N. Regulation of translation initiation by FRAP/mTOR. Genes Dev. 2001;15(7):807-826.

39. Pascual J, Boletis IN, Campistol JM. Everolimus (Cerican) in renal transplantation: a review of clinical trial data, current usage, and future directions. Transplant Rev. 2006;20:1-18.

40. Eisen HJ, Tuzcu M, Dorent R, et al. Everolimus for the prevention of allograft rejection and vasculopathy in cardiac-transplant patients. $N$ Engl J Med. 2003;349:847-858.

41. Boulay A, Zumstein-Mecker S, Stephan C, et al. Antitumor efficacy of intermittent treatment schedules with the rapamycin derivative RAD001 correlates with prolonged inactivation of ribosomal protein S6 kinase 1 in peripheral blood mononuclear cells. Cancer Res. 2004;64(1):252-261.

42. Tanaka C, O'Reilly T, Kovarik JM, et al. Identifying optimal biologic doses of everolimus (RAD001) in patients with cancer based on the modeling of preclinical and clinical pharmacokinetic and pharmacodynamic data. J Clin Oncol. 2008;26(10):1596-1602.

43. Tabernero J, Rojo F, Calvo E, et al. Dose- and schedule-dependent inhibition of the mammalian target of rapamycin pathway with everolimus: a phase I tumor pharmacodynamic study in patients with advanced solid tumors. J Clin Oncol. 2008;26(10):1603-1610.

44. Everolimus-summary of product characteristics. Available from: http:// www.ema.europa.eu/docs/en_GB/document_library/EPAR_-_Product_Information/human/001038/WC500022814.pdf. Accessed August 26, 2016.

45. Motzer RJ, Bacik J, Schwartz LH, et al. Prognostic factors for survival in previously treated patients with metastatic renal cell carcinoma. J Clin Oncol. 2004;22(3):454-463.

46. Motzer RJ, Escudier B, Oudard S, et al; RECORD-1 Study Group. Efficacy of everolimus in advanced renal cell carcinoma: a double-blind, randomised, placebo-controlled phase III trial. Lancet. 2008;372(9637): 449-456.

47. Motzer RJ, Agarwal N, Beard C, et al. NCCN clinical practice guidelines in oncology: kidney cancer. J Natl Compr Canc Netw. 2009;7(6): 618-630.
48. Amato RJ, Jac J, Giessinger S, Saxena S, Willis JP. A phase 2 study with a daily regimen of the oral mTOR inhibitor RAD001 (everolimus) in patients with metastatic clear cell renal cell cancer. Cancer. 2009;115(11):2438-2446.

49. Calvo E, Escudier B, Motzer RJ, et al. Everolimus in metastatic renal cell carcinoma: subgroup analysis of patients with 1 or 2 previous vascular endothelial growth factor receptor-tyrosine kinase inhibitor therapies enrolled in the phase III RECORD-1 study. Eur J Cancer. 2012;48(3):333-339.

50. Motzer RJ, Escudier B, Oudard S, et al. Phase 3 trial of everolimus for metastatic renal cell carcinoma: final results and analysis of prognostic factors. Cancer. 2010;116(18):4256-4265.

51. Grünwald V, Karakiewicz PI, Bavbek SE, et al; REACT Study Group. An international expanded-access programme of everolimus: addressing safety and efficacy in patients with metastatic renal cell carcinoma who progress after initial vascular endothelial growth factor receptor-tyrosine kinase inhibitor therapy. Eur J Cancer. 2012;48(3):324-332.

52. Choueiri TK, Escudier B, Powles T, et al; METEOR Investigators. Cabozantinib versus everolimus in advanced renal-cell carcinoma. $N$ Engl J Med. 2015;373(19):1814-1823.

53. Motzer RJ, Escudier B, McDermott DF, et al; CheckMate 025 Investigators. Nivolumab versus everolimus in advanced renal-cell carcinoma. N Engl J Med. 2015;373(19):1803-1813.

54. Choueiri TK, Escudier BJ, Powles T, et al. Cabozantinib versus everolimus in advanced renal cell carcinoma (METEOR): final results from a randomised, open-label, phase 3 trial. Lancet Oncol. 2016; 17(7):919-927.

55. Powles T, Motzer RJ, Escudier BJ, et al. Outcomes based on prior VEGFR TKI and PD-1 checkpoint inhibitor therapy in METEOR, a randomized phase 3 trial of cabozantinib (C) vs everolimus (E) in advanced renal cell carcinoma (RCC). J Clin Oncol. 2016;34 Suppl:abstr 4557.

56. Escudier BJ, Powles T, Motzer RJ, et al. Efficacy of cabozantinib (C) vs everolimus (E) in patients (pts) with advanced renal cell carcinoma (RCC) and bone metastases (mets) from the phase III METEOR study. J Clin Oncol. 2016;34 Suppl:abstr 4558.

57. Motzer RJ, Bacik J, Murphy BA, Russo P, Mazumdar M. Interferon-alfa as a comparative treatment for clinical trials of new therapies against advanced renal cell carcinoma. J Clin Oncol. 2002;20(1):289-296.

58. Heng DY, Xie W, Regan MM, et al. Prognostic factors for overall survival in patients with metastatic renal cell carcinoma treated with vascular endothelial growth factor-targeted agents: results from a large, multicenter study. J Clin Oncol. 2009;27(34):5794-5799.

59. Rini BI, Escudier B, Tomczak P, et al. Comparative effectiveness of axitinib versus sorafenib in advanced renal cell carcinoma (AXIS): a randomised phase 3 trial. Lancet. 2011;378(9807):1931-1939.

60. Dranitsaris G, Schmitz S, Broom RJ. Small molecule targeted therapies for the second-line treatment for metastatic renal cell carcinoma: a systematic review and indirect comparison of safety and efficacy. $J$ Cancer Res Clin Oncol. 2013;139(11):1917-1926.

61. Leung HW, Chan AL, Lin SJ. Indirect comparisons of efficacy and safety between seven newer targeted agents for metastatic renal cell carcinoma: a network meta-analysis of randomised clinical trials. Mol Clin Oncol. 2014;2(5):858-864.

62. Motzer RJ, Alyasova A, Ye D, et al. Phase II trial of second-line everolimus in patients with metastatic renal cell carcinoma (RECORD-4). Ann Oncol. 2016;27(3):441-448.

63. Motzer RJ, Barrios $\mathrm{CH}$, Kim TM, et al. Phase II randomized trial comparing sequential first-line everolimus and second-line sunitinib versus first-line sunitinib and second-line everolimus in patients with metastatic renal cell carcinoma. J Clin Oncol. 2014;32(25):2765-2772.

64. Davis ID, Long A, Yip S, et al. EVERSUN: A phase 2 trial of alternating sunitinib and everolimus as first line therapy for advanced renal cell carcinoma. Ann Oncol. 2015;26(6):1118-1123.

65. Thomas GV, Tran C, Mellinghoff IK, et al. Hypoxia-inducible factor determines sensitivity to inhibitors of mTOR in kidney cancer. Nat Med. 2006;12(1):122-127.

66. Hainsworth JD, Spigel DR, Burris HA 3rd, Waterhouse D, Clark BL, Whorf R. Phase II trial of bevacizumab and everolimus in patients with advanced renal cell carcinoma. J Clin Oncol. 2010;28(13):2131-2136. 
67. Ravaud A, Barrios CH, Alekseev B, et al. RECORD-2: phase II randomized study of everolimus and bevacizumab versus interferon $\alpha-2 \mathrm{a}$ and bevacizumab as first-line therapy in patients with metastatic renal cell carcinoma. Ann Oncol. 2015;26(7):1378-1384.

68. Rodrigues HV, Ke D, Lim J, et al. Phase I combination of pazopanib and everolimus in PIK3CA mutation positive/PTEN loss patients with advanced solid tumors refractory to standard therapy. Invest New Drugs. 2015;33(3):700-709.

69. Motzer RJ, Hutson TE, Glen H, et al. Lenvatinib, everolimus, and the combination in patients with metastatic renal cell carcinoma: a randomized, phase 2, open-label, multicenter trial. Lancet Oncol. 2015; 16(15):1473-1482.

70. Broom RJ, Hinder V, Sharples K, et al. Everolimus and zoledronic acid in patients with renal cell carcinoma with bone metastases: a randomized first-line phase II trial. Clin Genitourin Cancer. 2015;13(1): $50-58$.

71. Hudes G, Carducci M, Tomczak P, et al. Temsirolimus, interferon alfa, or both for advanced renal-cell carcinoma. N Engl J Med. 2007; 356(22):2271-2281.

72. Buti S, Bersanelli M. Non-clear-cell renal carcinoma therapy: handle with care. Lancet Oncol. 2016;17(3):270-271.

73. Koh Y, Lim HY, Ahn JH. Phase II trial of everolimus for the treatment of nonclear-cell renal cell carcinoma. Ann Oncol. 2013;24(4):1026-1031.

74. Escudier B, Bracarda S, Maroto JP, et al. Open-label, phase II raptor study of everolimus (EVE) for papillary mRCC: efficacy in type 1 and type 2 histology. J Clin Oncol. 2014;4 Suppl:abstr 410.

75. Tannir NM, Jonasch E, Albiges L, et al. Everolimus versus sunitinib prospective evaluation in metastatic non-clear cell renal cell carcinoma (ESPN): a randomized multicenter phase 2 trial. Eur Urol. 2016;69(5): 866-874.

76. Armstrong AJ, Halabi S, Eisen T, et al. Everolimus versus sunitinib for patients with metastatic non-clear cell renal cell carcinoma (ASPEN): a multicentre, open-label, randomised phase 2 trial. Lancet Oncol. 2016;17(3):378-388.

77. Darwish OM, Kapur P, Youssef RF, et al. Cumulative number of altered biomarkers in mammalian target of rapamycin pathway is an independent predictor of outcome in patients with clear cell renal cell carcinoma. Urology. 2013;81(3):581-586.

78. Cho D, Signoretti S, Dabora S, et al. Potential histologic and molecular predictors of response to temsirolimus in patients with advanced renal cell carcinoma. Clin Genitourin Cancer. 2007;5(6):379-385.

79. Li S, Kong Y, Si L, et al. Phosphorylation of mTOR and S6RP predicts the efficacy of everolimus in patients with metastatic renal cell carcinoma. BMC Cancer. 2014;14:376.

80. Knoll M, Macher-Goeppinger S, Kopitz J, et al. The ribosomal protein S6 in renal cell carcinoma: functional relevance and potential as biomarker. Oncotarget. 2016;7(1):418-432.

81. Manning BD. Balancing Akt with S6K: implications for both metabolic diseases and tumorigenesis. J Cell Biol. 2004;167(3):399-403.
82. Taha C, Liu Z, Jin J, Al-Hasani H, Sonenberg N, Klip A. Opposite translational control of GLUT1 and GLUT4 glucose transporter mRNAs in response to insulin. Role of mammalian target of rapamycin, protein kinase $b$, and phosphatidylinositol 3-kinase in GLUT1 mRNA translation. J Biol Chem. 1999;274(46):33085-33091.

83. Voss MH, Molina AM, Motzer RJ. mTor inhibitors in advanced renal cell carcinoma. Hematol Oncol Clin North Am. 2011;25(4):835-852.

84. Kovarik JM, Hartmann S, Hubert M, et al. Pharmacokinetic and pharmacodynamic assessments of HMG-CoA reductase inhibitors when coadministered with everolimus. J Clin Pharmacol. 2002;42(2): 222-228.

85. White DA, Camus P, Endo M, et al. Noninfectious pneumonitis after everolimus therapy for advanced renal cell carcinoma. Am J Respir Crit Care Med. 2010;182(3):396-403.

86. Aaronson NK, Ahmedzai A, Bergman B, et al. The European Organization for Research and Treatment of Cancer QLQ-C30: a quality-of-life instrument for use in international clinical trials in oncology. $J$ Natl Cancer Inst. 1993;85(5):365-376.

87. Cella D, Yount S, Brucker PS, et al. Development and validation of a scale to measure disease-related symptoms of kidney cancer. Value Health. 2007;10(4):285-293.

88. Beaumont JL, Butt Z, Baladi J, et al. Patient-reported outcomes in a phase iii study of everolimus versus placebo in patients with metastatic carcinoma of the kidney that has progressed on vascular endothelial growth factor receptor tyrosine kinase inhibitor therapy. Oncologist. 2011;16(5):632-640.

89. Pitt M, Crathorne L, Moxham T, Bond M, Hyde C. Everolimus for the second-line treatment of advanced and/or metastatic renal cell cancer: a critique of the submission from Novartis. Health Technol Assess. 2010;14(Suppl 2):41-46.

90. Casciano R, Chulikavit M, Di Lorenzo G, et al. Economic evaluation of everolimus versus sorafenib for the treatment of metastatic renal cell carcinoma after failure of first-line sunitinib. Value Health. 2011;14(6):846-851.

91. Mihajlović J, Pechlivanoglou P, Sabo A, Tomić Z, Postma MJ. Costeffectiveness of everolimus for second-line treatment of metastatic renal cell carcinoma in Serbia. Clin Ther. 2013;35(12):1909-1922.

92. Sherman SA, Wang X, Amzal B, et al. A weighted-adjusted indirect comparison of everolimus (EVE) versus axitinib (AXI) in second-line metastatic renal cell carcinoma (mRCC) patients who previously failed sunitinib therapy. Poster presented at: 2014 Genitourinary Cancers Symposium; January 30, 2014 to February 1, 2014; San Francisco, CA.

93. Perrin A, Sherman S, Pal S, et al. Lifetime cost of everolimus vs axitinib in patients with advanced renal cell carcinoma who failed prior sunitinib therapy in the US. J Med Econ. 2015;18(3):200-209.

94. Vrdoljak E, Torday L, Szczylik C, Kharkevich G, Bavbek S, Sella A. Pharmacoeconomic and clinical implications of sequential therapy for metastatic renal cell carcinoma patients in Central and Eastern Europe. Expert Opin Pharmacother. 2016;17(1):93-104.
Core Evidence

\section{Publish your work in this journal}

Core Evidence is an international, peer-reviewed open-access journal evaluating the evidence underlying the potential place in therapy of drugs throughout their development lifecycle from preclinical to post launch. The focus of each review is to evaluate the case for a new drug or class in outcome terms in specific indications and patient groups.

\section{Dovepress}

The manuscript management system is completely online and includes a very quick and fair peer-review system, which is all easy to use. Visit http://www.dovepress.com/testimonials.php to read real quotes from published authors. 